\title{
Synthesis of core-shell titanium dioxide nanoparticles with water-soluble shell of poly(methacrylic acid)
}

\author{
E. L. Krasnopeeva ${ }^{1,2}$, E. Yu. Melenevskaya ${ }^{1}$, O. A. Shilova ${ }^{2}$, A. M. Nikolaev ${ }^{2}$, A. V. Yakimansky ${ }^{1}$ \\ ${ }^{1}$ Institute of Macromolecular Compounds, Russian Academy of Sciences, St. Petersburg, Russia \\ ${ }^{2}$ Grebenshchikov Institute of Silicate Chemistry, Russian Academy of Sciences, St. Petersburg, Russia \\ opeeva@gmail.com
}

PACS 61.46.+w, 68.47.Pe

DOI 10.17586/2220-8054-2021-12-3-336-345

The article is devoted to the covalent modification of the surface of titanium dioxide nanoparticles with polymethacrylic acid using the method of controlled atom transfer radical polymerization. For the first time, core-shell titanium dioxide nanoparticles with water-soluble shell of poly(methacrylic acid) were obtained.

Keywords: modification of nanoparticles, titanium dioxide, controlled radical polymerization, polymethacrylic acid, core-shell nanoparticles.

Received: 2 December 2020

Revised: 9 April 2021

\section{Introduction}

In the recent years, nanosized titania and titania-based nanocomposites have become increasingly popular materials in the industrial-scale manufacturing of many products, agriculture, environmental science, and power engineering due to their photocatalytic [1-6], photoluminescent [7,8], semiconductor [9-11], pigment [12], and biological [13-15] properties. In particular, titanium dioxide nanoparticles are widely used in agriculture for the photocatalytic decomposition of pesticides [16-31], solar energy-assisted photocatalytic water purification (review [16] and references therein), plant disease control [32-34]. One of the most important application areas of $\mathrm{TiO}_{2}$ nanoparticles in agriculture is treatment of crop seeds aimed at accelerating seed germination and crop vegetation [35-40]. The possibility of this practical application of titanium dioxide is related to its capability for photocatalytic activation of oxygen, which yields reactive oxygen species such as peroxide and hydroxide radicals and ions. As a result, stress tolerance of seeds is enhanced, their ability to absorb water and oxygen increase [36]. Besides, treatment of seeds with titanium dioxide nanoparticles leads to enhanced nitrogen binding by plants, increase in chlorophyll and protein contents in plants [38].

In order to increase efficiency of $\mathrm{TiO}_{2}$-based photocatalytic systems, it is necessary to use this substance in the form of stabilized aqueous dispersions (which are generated, for instance, upon interaction with triethanolamine [41]), or in the form of core-shell nanoparticles with $\mathrm{TiO}_{2}$ core and a water-soluble shell. The most promising synthetic method for these core-shell structures consists in modifying titanium dioxide nanoparticle surfaceswith covalently grafted chains of water-soluble hydrophilic polymers. To date, a relatively large number of works devoted to modification of $\mathrm{TiO}_{2}$ nanoparticles with various polymers have been published. The most common method is controlled atom transfer radical polymerization (ATRP) of vinyl monomers involving $\alpha$-Br-ester groups immobilized on nanoparticle surface [42-54]. In most cases, this immobilization is preceded by modification of $\mathrm{TiO}_{2}$ surface with amino groups in the process of treatment of nanoparticles with 3-aminopropyltriethoxysilane [42, 48-51, 53] or dopamine [43]. Then, the obtained nanoparticles are treated with bromoanhydrides of 2-bromopropionic or 2bromo-isobutyric acids [42,43,48-51,53], which results in immobilization of ATRP-initiating $\alpha$-Br-ester groups on nanoparticle surface. In some cases, $\mathrm{TiO}_{2}$ nanoparticles are immediately treated with 2-Br-isobutyroyl bromide [44].

It should be noted that there are virtually no literature data on modification of $\mathrm{TiO}_{2}$ nanoparticle surfaces with water-soluble polymers. A small number of published papers report the synthesis of titanium dioxide and zinc oxide nanoparticles modified with poly(N,N-diethylaminoethyl methacrylate), which were used as nanocontainers for anticancer preparations [44]. Titanium dioxide nanoparticles modified with ionized poly(styrene sulfonic acid) were used as ion exchangers for $\mathrm{Ag}^{+}$; the products were intended for applications as $\mathrm{TiO}_{2} / \mathrm{Ag}$ binary nanocomposite photocatalysts [45] and one of components of proton-conducting membranes [54]. There are also papers reporting the synthesis of $\mathrm{TiO}_{2}$ nanoparticles modified with poly(oligoethylene glycol) methacrylate [47] and poly(N-isopropyl acrylamide); the latter demonstrate self-flocculation in aqueous medium at temperatures above low critical solution temperature of poly(N-isopropyl acrylamide) [51,52]. In addition, block copolymers of styrene and acrylic acid were used as micellar nanoreactors for the synthesis of $\mathrm{TiO}_{2}$ nanoparticles and stabilization of $\mathrm{TiO}_{2}$ aqueous dispersions [55]. 
In the present work, we synthesized core-shell $\mathrm{TiO}_{2}$ nanoparticles modified with water-soluble poly(methacrylic acid) for the first time. The two-stage grafting method described above was used for immobilization of 2-Br-isobutyrate groups on the surface of titanium dioxide; the method involved successive treatment of nanoparticles with 3-aminopropyltriethoxysilane and 2-Br-isobutyroyl bromide. Then, the obtained $\mathrm{TiO}_{2}$-based macroinitiators were

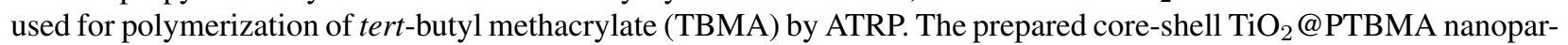
ticles with grafted PTBMA chains were subjected to acidic hydrolysis; ester groups of the grafted chains were converted to carboxylategroups, and $\mathrm{TiO}_{2} @$ PMAA core-shell nanoparticles with poly(methacrylic acid) shells were obtained. In order to determine lengths of the grafted chains, they were isolated by selective alkaline hydrolysis of ester bonds that connect polymer chains to $\mathrm{TiO}_{2}$ surface; molecular masses and molecular mass distributions were estimated by size exclusion liquid chromatography (SEC).

The structure of nanoparticles at all stages of synthesis was confirmed by IR spectroscopy and solid state ${ }^{13} \mathrm{C}$ NMR spectroscopy.

\section{Experimental: materials}

3-Aminopropyltriethoxysilane (99\%, Acros Organics), N,N-dimethylformamide (DMF) (reagent grade, Vekton, Russia), and $N, N, N^{\prime}, N^{\prime}, N^{\prime \prime}$-pentamethyldiethylenetriamine (PMDETA) (99\%, Aldrich) were used without additional purification. Methylene chloride (reagent grade, Vekton, Russia) and toluene (analytical grade, Vekton, Russia) were dried by heating over anhydrous calcium hydride ( $99.9 \%$, Aldrich), then distilled under vacuum. The ionic liquid (1-butyl-3-methylimidazolium chloride (BMIMCl) ( $\geq 98.0 \%$ (Aldrich)), glacial acetic acid (reagent grade, Vekton, Russia), trifluoroacetic acid (99\%, Aldrich), copper (I) bromide (99.999\%, Aldrich), 2-bromo-isobutyroyl bromide (98\%, Aldrich) were used without additional purification. Tert-butyl methacrylate (TBMA) (98\%, Aldrich) was twice distilled under vacuum before use, commercial $\mathrm{TiO}_{2}$ rutile nanopowder (Plasmotherm) was used for the modification.

\section{Experimental: methods}

\section{1. $\mathrm{TiO}_{2}$ nanoparticles}

SEM image of particles is presented in Fig. 1. According to these data, the particles have the size of $100-300 \mathrm{~nm}$,

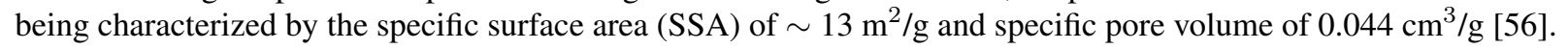

$\mathrm{X}$-Ray diffraction of particles is presented in Fig. 2.

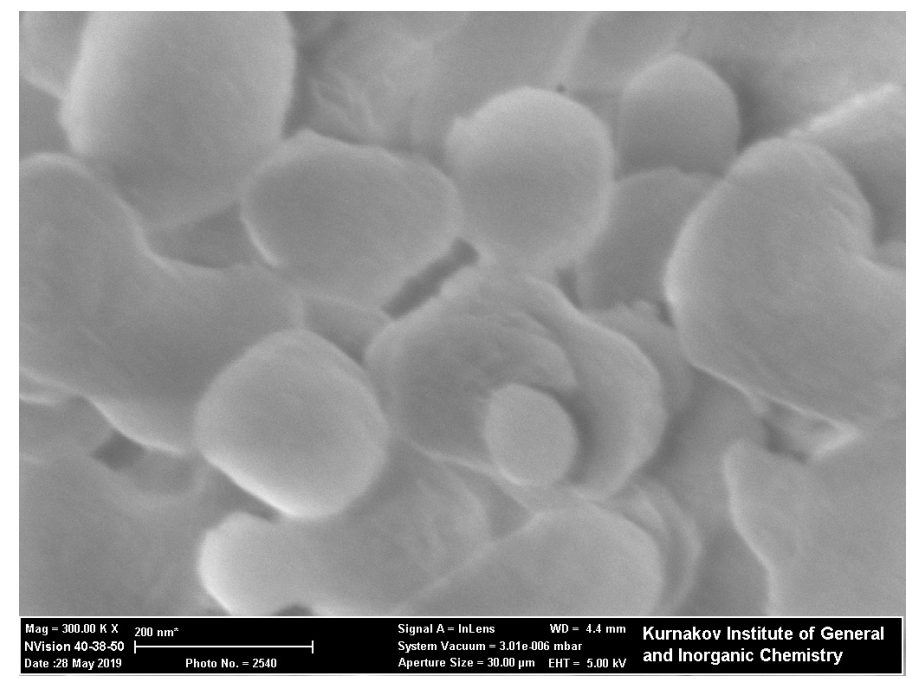

FIG. 1. SEM image of $\mathrm{TiO}_{2}$ nanoparticles

\subsection{Synthesis of $\mathrm{TiO}_{2}$ nanoparticles modified with 3-aminopropyltriethoxysilane (APTES)}

Titanium dioxide particles $(0.73 \mathrm{~g})$ were annealed under vacuum at $120{ }^{\circ} \mathrm{C}$ for $4 \mathrm{~h}$ in order to remove physically adsorbed water [57]. Then the product was cooled down to room temperature, and DMF (10 mL) was recondensed into the reaction vessel, and the mixture was subjected to ultrasound treatment for $30 \mathrm{~min}$. Then the mixture was degassed thrice, and argon was passed through the system; APTES $(0.5 \mathrm{~mL})$ was added at cooling in an ice bath and at constant stirring. The mixture was left to stand for $24 \mathrm{~h}$ at constant agitation under anargon atmosphere at room temperature. 


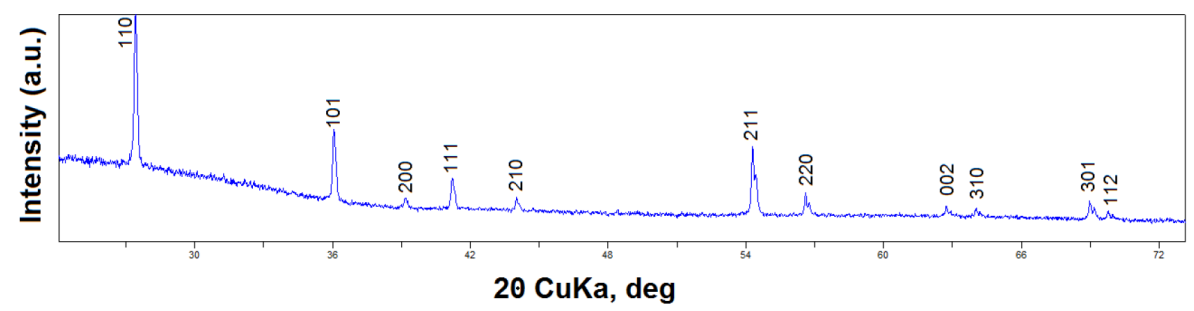

FIG. 2. X-Ray diffractogram of the $\mathrm{TiO}_{2}$

The particles were isolated by centrifugation, washed thrice with DMF and thrice with methylene chloride. Yield: $0.74 \mathrm{~g}$.

\subsection{Synthesis of $\mathrm{TiO}_{2}$-APTES-BiB macroinitiators based on $\mathrm{TiO}_{2}$-APTES}

Titanium dioxide nanoparticles modified with APTES $\left(\mathrm{TiO}_{2}\right.$-APTES, $0.5 \mathrm{~g}$ ) were heated at $110{ }^{\circ} \mathrm{C}$ under vacuum for $2 \mathrm{~h}$. Dry toluene $(25 \mathrm{~mL})$ was recondensed into the reaction flask; the mixture was degassed thrice, andargon was passed through the system; then 2-bromo-isobutyroyl bromide (BiB, $2 \mathrm{~mL})$ was added. The reaction mixture was exposed at room temperature and constant stirring for $24 \mathrm{~h}$. The product was precipitated into deionized water and washed thrice with subsequent centrifugation. The final product was obtained in the form of white powder. Yield: $0.83 \mathrm{~g}$.

\subsection{Synthesis of $\mathrm{TiO}_{2}$-APTES-BiB-PTBMA core-shell nanoparticles with poly(tert-butylmethacrylate) (PTBMA) shells}

The initiator $(0.2 \mathrm{~g})$ was put into the reaction flask together with $10 \mathrm{~g}$ of the ionic liquid (butyl-methyl imidazolium chloride), heated to $80^{\circ} \mathrm{C}$ at constant stirring, degassed and subjected to ultrasound treatment for 30 min. Then, argon was passed through the flask; $\mathrm{CuBr}(0.063 \mathrm{~g})$ and PMDETA $(0.7 \mathrm{~mL})$ were added. Then preliminarily distilled TBMA was added in the amounts indicated below. The mixture was exposed at $80{ }^{\circ} \mathrm{C}$ with constant agitation for $24 \mathrm{~h}$. The synthesized particles were precipitated into excess distilled water and dried in air. The final product was obtained in the form of white powder.

The following samples containing various amounts of PTBMA were synthesized by addition of 7.5, 2.5, and $1 \mathrm{~mL}$ of TBMA: $\mathrm{TiO}_{2}$-APTES-BiB-PTBMA-1, $\mathrm{TiO}_{2}$-APTES-BiB-PTBMA-2, and $\mathrm{TiO}_{2}$-APTES-BiB-PTBMA-3, respectively.

\subsection{Elimination of grafted PTBMA chains by alkaline hydrolysis of TiO $_{2}$-APTES-BiB-PTBMA core-shell nanoparticles}

The particles were put into $2 \mathrm{wt} . \%$ solution of $\mathrm{KOH}$ in methanol at $65^{\circ} \mathrm{C}$ and exposed for $16 \mathrm{~h}$. Linear PTBMA was precipitated into the methanol:water mixture and dried until constant weight was achieved.

\subsection{Synthesis of $\mathrm{TiO}_{2}$-APTES-BiB-PMAA core-shell nanoparticles with poly(methacrylic acid) (PMAA) shells}

The synthesized $\mathrm{TiO}_{2}$-APTES-BiB-PTBMA-1, $\mathrm{TiO}_{2}$-APTES-BiB-PTBMA-2, and $\mathrm{TiO}_{2}$-APTES-BiB-PTBMA-3 samples were dissolved in minimal amount of methylene chloride; trifluoroacetic acid (small excess) was added, then the mixture was exposed for $24 \mathrm{~h}$ at room temperature and constant stirring. The formed precipitate was washed with dichloromethane until neutral $\mathrm{pH}$ was reached, and then dried in air. Titanium dioxide particles modified with watersoluble poly(methacrylic acid) chains of various lengths $\left(\mathrm{TiO}_{2}\right.$-APTES-BiB-PMAA-1, $\mathrm{TiO}_{2}-\mathrm{APTES}-\mathrm{BiB}-\mathrm{PMAA}-2$, and $\mathrm{TiO}_{2}$-APTES-BiB-PMAA-3) were obtained.

\subsection{X-Ray diffraction}

$\mathrm{X}$-Ray diffraction was carried out using Rigaku MiniFlexII diffractometer with $\mathrm{CuK} \alpha$ radiation in the $2 \theta$ range $5-75^{\circ}$, with step $0.02^{\circ}$ at $5^{\circ} / \mathrm{min}$ speed. Crystal scattering domain (CSD) length was calculated with Debye-Scherrer formula using 110 reflections.

\subsection{IR spectroscopy}

IR Fourier transform spectra were obtained with the aid of an IRAffinity-1S spectrometer (Shimadzu) equipped with a Quest attenuated total reflectance attachment (Specac) (diamond prism, spectral range $7800-400 \mathrm{~cm}^{-1}$ ). 


\subsection{NMR spectroscopy}

Solid state ${ }^{13} \mathrm{C}$ NMR spectra were recorded using a Bruker Avance $400 \mathrm{SB}$ instrument (1H: $400 \mathrm{MHz}$ ).

\subsection{Size exclusion chromatography}

The samples were analysed with the aid of an Agilent-1260 Infinity chromatography setup equipped with two columns packed with PLgel MIXED-C sorbent (column dimensions: $7.5 \times 300 \mathrm{~mm}$; sorbent particle size: $5 \mu \mathrm{m}$ ). Elution proceeded in isocratic regime; dimethylformamide was used as an eluent. Molecular masses and polydispersity parameters were measured by multidetector gel permeating chromatography. Characteristics of polymers were determined from the data of refractometric and viscosimetric detectors used in combination with a light scattering detector, which makes it possible to manage without calibration standards.

\subsection{Scanning electron microscopy}

The SEM studies were performed with the aid of a Carl Zeiss N Vision 40 instrument at an accelerating voltage of $1 \mathrm{kV}$ and magnification of up to $\times 300000$.

\subsection{Thermogravimetry}

A DTG-60 setup (Shimadzu, Kyoto, Japan) was used for thermogravimetric (TGA) analysis to determine the amount of $\mathrm{OH}$-groups chemically bound to the surface of $\mathrm{TiO}_{2}$ nanoparticles, the samples being heated to $600{ }^{\circ} \mathrm{C}$ at a rate of $5^{\circ} \mathrm{C} / \mathrm{min}$ in air flow $(80 \mathrm{~mL} / \mathrm{min})$.

\section{Results and discussion}

$\mathrm{TiO}_{2}$ nanoparticles were studied by the TGA method in order to determine the amount of surface OH-groups bound covalently to $\mathrm{Ti}$ atoms. According to the procedure described in [57], the following equation was used to this aim:

$$
\# \mathrm{OH} / \mathrm{nm}^{2}=0.625 \times \frac{2\left(\Delta W_{T_{1} \rightarrow T_{2}}\right) N_{A}}{S S A \times M W_{\mathrm{H}_{2} \mathrm{O}}},
$$

where $\Delta W_{T_{1} \rightarrow T_{2}}$ is the weight loss fraction upon heating the sample from $T_{1}=120{ }^{\circ} \mathrm{C}$ (the annealing temperature at which physically adsorbed water is removed) to $T_{2}=600{ }^{\circ} \mathrm{C}$ (the temperature at which no chemically bound $\mathrm{OH}$-groups remain on the surface of titania nanoparticles [57]), $N_{A}$ is Avogadro number, $M W_{\mathrm{H}_{2} \mathrm{O}}$ is the molecular weight of water. As may be found from the TGA curve presented in Fig. 3, $\Delta W_{T_{1} \rightarrow T_{2}} \approx 0.0092$. Then, according to formula (1) with $S S A=13 \mathrm{~m}^{2} / \mathrm{g}$, the surface density of chemically bound OH-groups, \#OH $/ \mathrm{nm}^{2}=29.4 \mathrm{~nm}^{-2}$. This value corresponds to $\sim 3.822 \cdot 10^{20}$ chemically bound surface $\mathrm{OH}$-groups per $1 \mathrm{~g}$ of $\mathrm{TiO}_{2}$ nanoparticles.

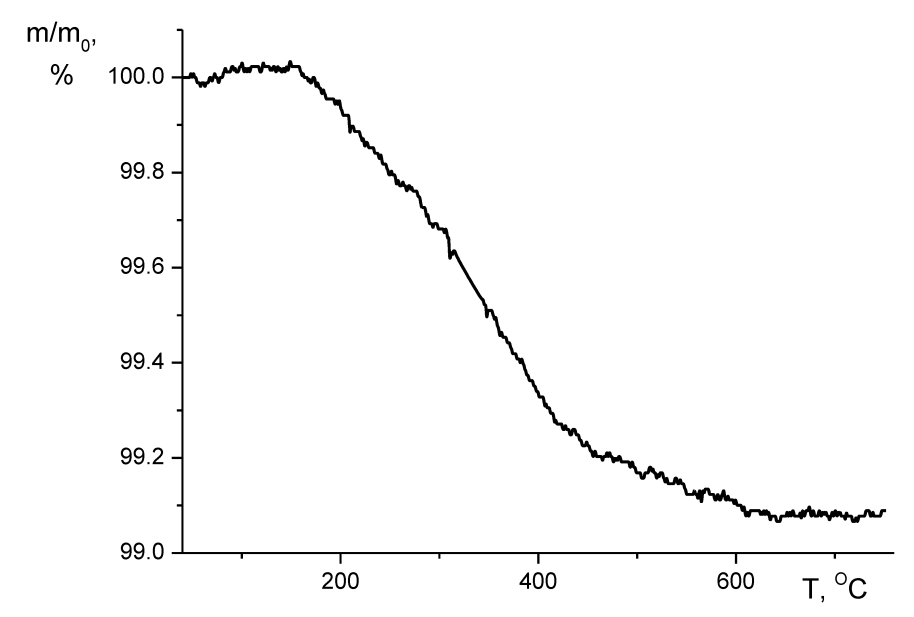

FIG. 3. TGA curve of the powder of $\mathrm{TiO}_{2}$ nanoparticles

The scheme of the synthesis of $\mathrm{TiO}_{2}$-APTES-BiB-PMAA core-shell particles with titanium dioxide cores and poly(methacrylic acid) shells included several stages; the synthesis scheme is presented in Fig. 4.

At the first stage, titanium dioxide nanoparticles were treated with APTES in order to graft primary amino groups onto nanoparticles' surface. The taken amount of APTES $(0.5 \mathrm{~g})$ corresponds to an approximately 5-fold molar excess 


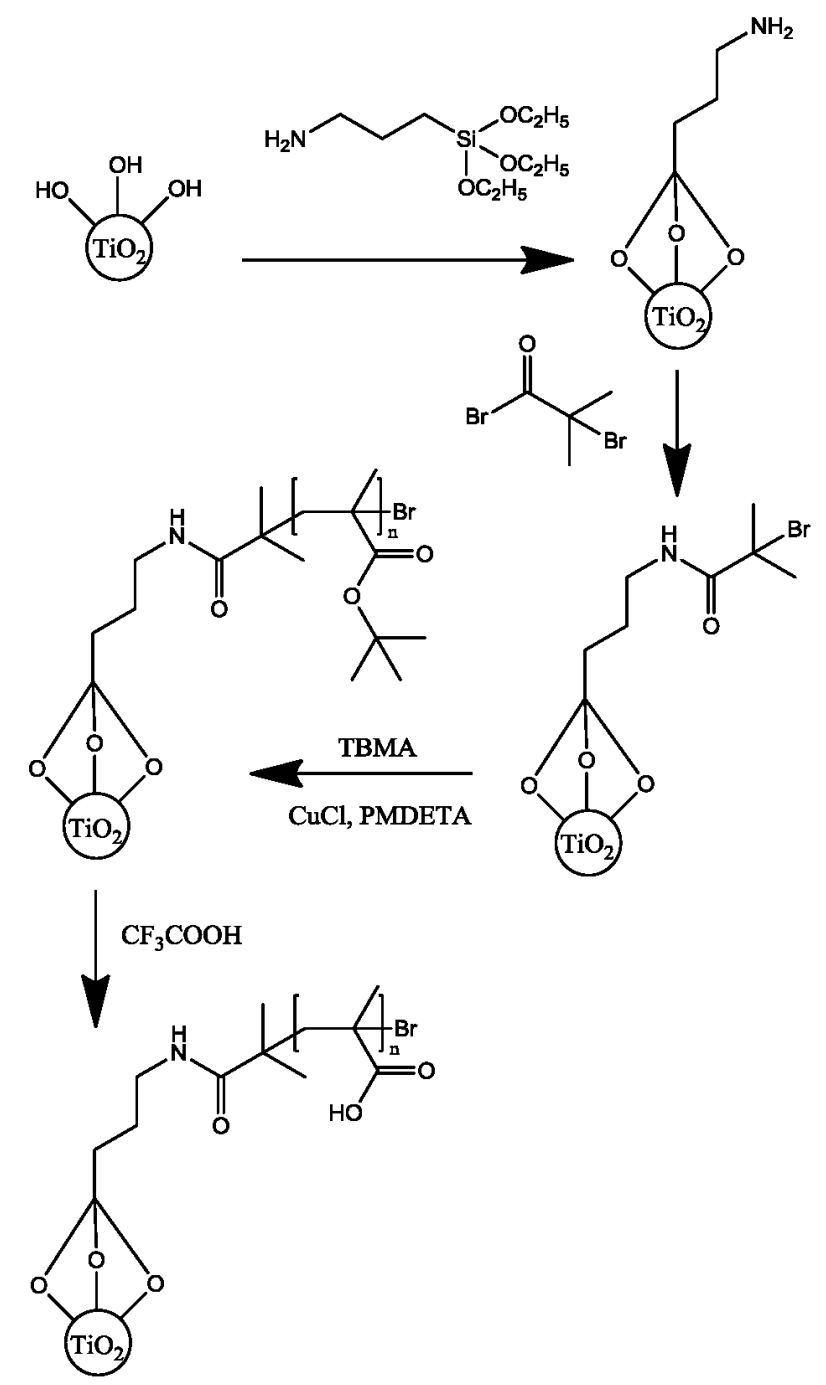

FIG. 4. Scheme of the synthesis of $\mathrm{TiO}_{2}$-APTES-BiB-PMAA core-shell particles with titanium dioxide cores and poly(methacrylic acid) shells

of APTES with respect to chemically bound surface OH-groups in the taken amount of annealed $\mathrm{TiO}_{2}$ nanoparticles $(0.73 \mathrm{~g})$. The presence of amino groups on the surface of the synthesized particles is confirmed by comparison of ${ }^{13} \mathrm{C}$ NMR spectra of the initial titanium dioxide nanoparticles (Fig. 5a) and the nanoparticles treated with APTES (Fig. 5b). The spectrum of the initial nanoparticles presented in Fig. 5a indicates that they have pure surface, i.e. there are no carbon-containing groups or compounds on $\mathrm{TiO}_{2}$.

Meanwhile, the spectrum of $\mathrm{TiO}_{2}$-APTES nanoparticles contains the signals attributed to carbon atoms of aminopropyl groups near 10, 25 and $45 \mathrm{ppm}$. In addition, the presence of surface amino groups is confirmed by comparison of IR spectra of the initial $\mathrm{TiO}_{2}$ nanoparticles before and after treatment with APTES (Fig. 6). The following bands appear in the spectra of APTES derivatives: (i) wide bands in the region $1560-1570 \mathrm{~cm}^{-1}$ attributed to deformation vibrations of primary amino groups [58]; (ii) $\mathrm{C}-\mathrm{N}$ stretching vibration band of APTES at $1323 \mathrm{~cm}^{-1}$ [58]; (iii) the bands near $1140 \mathrm{~cm}^{-1}$ assigned to valence vibrations of $\mathrm{C}-\mathrm{N}$ bond in primary amines [59].

At the second stage, surface amino groups of $\mathrm{TiO}_{2}$-APTES nanoparticles were acylated with 2-bromo-isobutyroyl bromide to graft 2-bromo-isobutyrate groups onto nanoparticles' surface; these fragments are able to initiate controlled atom transfer radical polymerization. ${ }^{13} \mathrm{C}$ NMR spectrum of the resulting $\mathrm{TiO}_{2}$-APTES-BiB nanoparticles is presented in Fig. 5c. Comparison of this spectrum with NMR spectrum of $\mathrm{TiO}_{2}$-APTES (Fig. 5b) demonstrates that the formercontains new signals attributed to methyl carbon atoms (32 ppm), quaternary carbon atoms (52 ppm), and carbonyl atoms in 2-bromo-isobutyrate fragments $(170-180 \mathrm{ppm})$. Thus, the ${ }^{13} \mathrm{C}$ NMR spectroscopy data confirm successful preparation of $\mathrm{TiO}_{2}$-APTES-BiB nanoparticles with surface 2-bromo-isobutyrate groups. 
(a)

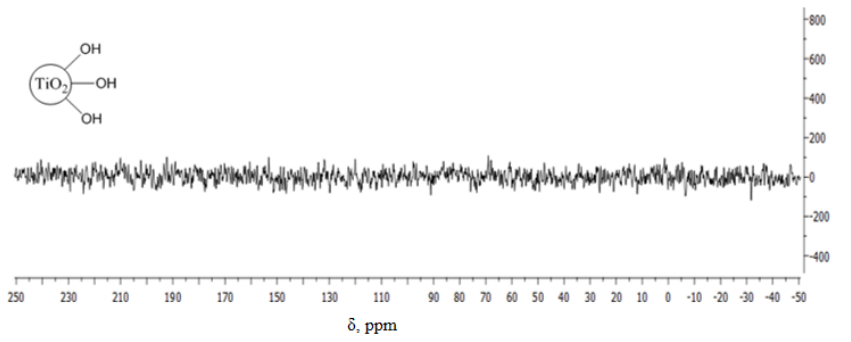

(b)
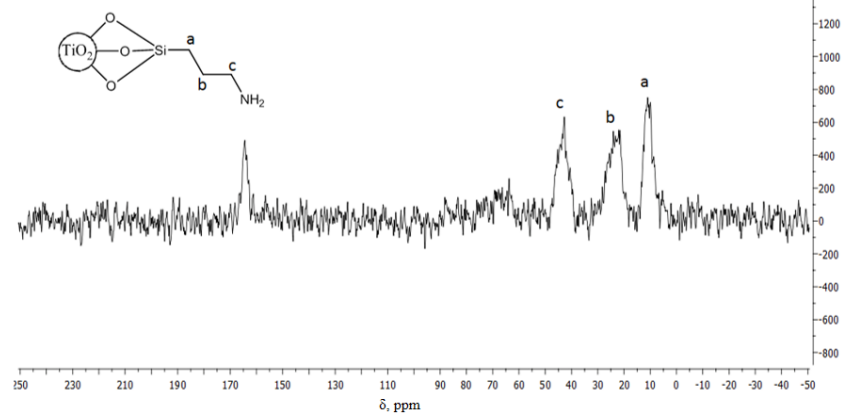

(c)

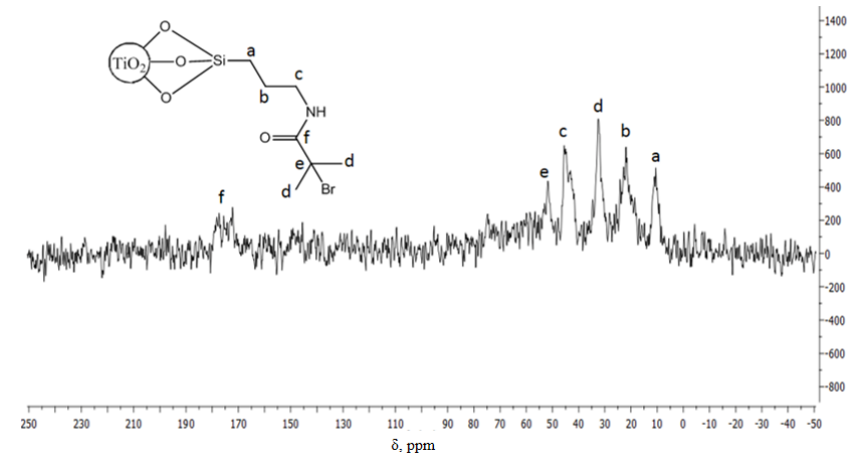

(d)

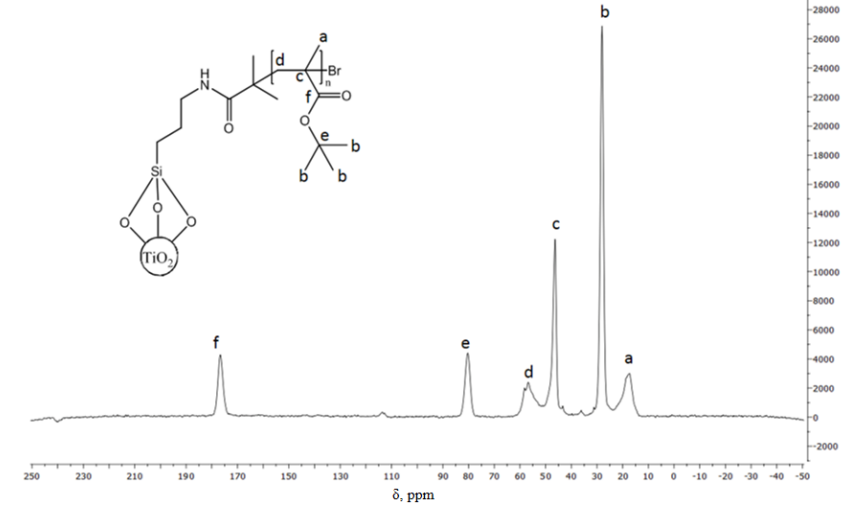

(e)

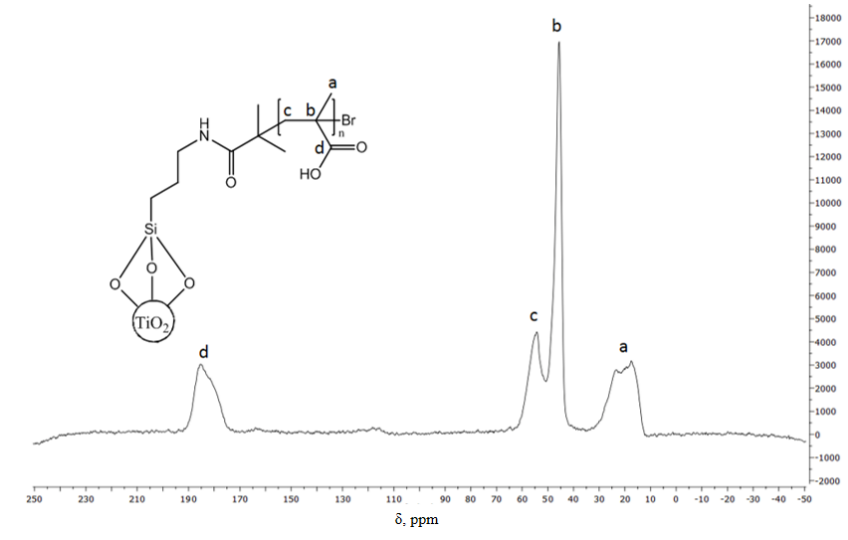

FIG. 5. Solid state ${ }^{13} \mathrm{C}$ NMR spectra of the initial titanium dioxide (a), $\mathrm{TiO}_{2}$-APTES (b), $\mathrm{TiO}_{2}$ APTES-BiB (c), $\mathrm{TiO}_{2}$-APTES-BiB-PTBMA (d) and $\mathrm{TiO}_{2}$-APTES-BiB-PMAA particle (e) 


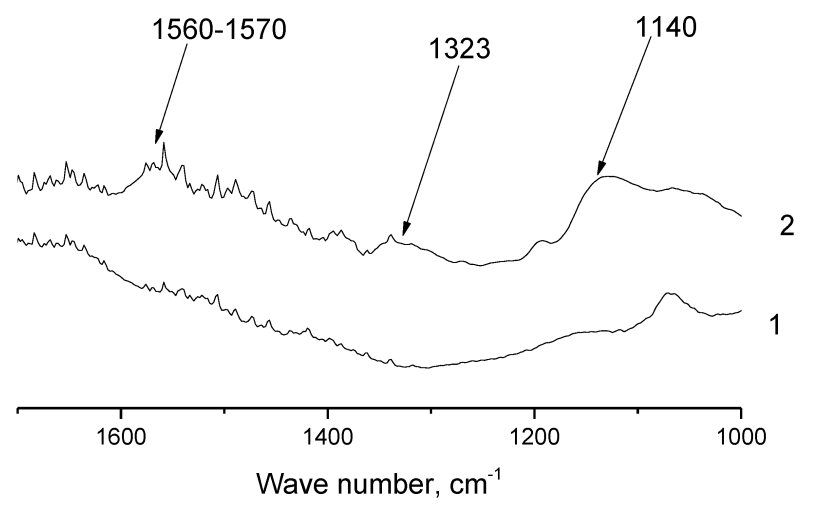

FIG. 6. IR spectra of the initial titanium oxide (1) and $\mathrm{TiO}_{2}$-APTES nanoparticles (2)

The synthesized $\mathrm{TiO}_{2}$-APTES-BiB nanoparticles were used in polymerization of tert-butyl methacrylate according to ATRP mechanism. The $\mathrm{TiO}_{2}$-APTES-BiB-PTBMA nanoparticles were synthesized; their ${ }^{13} \mathrm{C}$ NMR spectrum (Fig. 5d) virtually coincides with that of poly(tert-butyl methacrylate). It includes signals related to all PTBMA carbon atoms: methylene group $(\sim 55 \mathrm{ppm})$ and $\alpha$-carbon atom $(\sim 45 \mathrm{ppm})$ of PTBMA backbone, methyl group at $\alpha$-carbon $(\sim 18 \mathrm{ppm})$, signals of carbonyl atoms $(\sim 180 \mathrm{ppm})$, quaternary carbon atoms $(\sim 80 \mathrm{ppm})$ and methyl carbon atoms $(\sim 28 \mathrm{ppm})$ of side ester groups. It should be noted that signals of $\mathrm{TiO}_{2}-\mathrm{APTES}-\mathrm{BiB}$ macroinitiator cannot be registered due to its extremely low amount in $\mathrm{TiO}_{2}$-APTES-BiB-PTBMA samples.

The grafted PTBMA chains were eliminated from $\mathrm{TiO}_{2}$-APTES-BiB-PTBMA nanoparticles in the process of alkaline hydrolysis, which destructs the ester bonds connecting polymer chains to macroinitiator fragments. Conditions of alkaline hydrolysis were selected so as to prevent transformation of side ester fragments of PTBMA [60]. The isolated linear PTBMA was analyzed by multidetector size exclusion liquid chromatography with the so-called triple detection (a combined analysis of the data provided by refractometric, viscosimetric and light scattering detectors [61]). It was found that the isolated PTBMA chains have the following characteristics: $M_{n}=70000, M_{w}=120000$, $M_{w} / M_{n}=1.7$. Thus, the PTBMA chains grafted onto the surface of titanium dioxide nanoparticles are long (polymerization degree about 500) and have relatively narrow molecular mass distributions.

At the last synthesis stage, $\mathrm{TiO}_{2}$-APTES-BiB-PTBMA nanoparticles were subjected to "dry" acidic hydrolysis that affected side ester groups of PTBMA chains. Hydrolysis proceeded under the action of anhydrous trifluoroacetic acid and was accompanied by release of gaseous isobutylene and transformation of ester groups into carboxylic fragments. As a result, we obtained $\mathrm{TiO}_{2}$-APTES-BiB-PMAA nanoparticles with water-soluble poly(methacrylic acid) shells, their polymerization degree being the same as that of the initial PTBMA chains. ${ }^{13} \mathrm{C}$ NMR spectrum of these nanoparticles given in Fig. 5e confirms the presence of poly(methacrylic acid) in the shell. Thus, the spectrum contains the signals attributed to methylene group atoms $(\sim 55 \mathrm{ppm})$ and $\alpha$-carbon atoms $(\sim 45 \mathrm{ppm})$ of PMAA backbone, the signals of methyl group at $\alpha$-carbon atom $(\sim 20 \mathrm{ppm})$ and carboxylic carbon atom $(\sim 185 \mathrm{ppm})$. At the same time, there are no peaks related to quaternary carbon atoms and methyl carbon atoms of side ester groups, which indicates complete transformation of $\mathrm{TiO}_{2}$-APTES-BiB-PTBMA into $\mathrm{TiO}_{2}$-APTES-BiB-PMAA.

According to the polymerization degree of $\sim 500$ of PMAA chains in the shell of $\mathrm{TiO}_{2}$-APTES-BiB-PMAA particles, the shell is $\sim 125 \mathrm{~nm}$ thick, taking into account that the monomer unit length of PMAA side chains is $\sim 0.25 \mathrm{~nm}$. The UV spectrum of the synthesized $\mathrm{TiO}_{2}$-APTES-BiB-PMAA nanoparticles in water solution is presented in Fig. 7.

As seen from Fig. 7, the spectrum shows a typical absorption of $\mathrm{TiO}_{2}$ cores below $400 \mathrm{~nm}$ [62].

\section{Conclusions}

Modification of nanoparticles surface with polymers is of great interest for various practical applications. The obtained $\mathrm{TiO}_{2}$-APTES-BiB-PMAA core-shell nanoparticles with a water-soluble shell can be used, in particular, for treatment of agricultural crop seeds with the purposes of enhancing their germination and increasing growth rate. Each nanoparticle contains photocatalytically active core of titanium dioxide that increases photosynthesis efficiency and poly(methacrylic acid) shell providing solubility of the product in water. It should be noted that the synthesis of titanium dioxide nanoparticles with grafted poly(methyl methacrylate) chains has been described in the literature [63]. However, water-soluble shells of poly(methacrylic acid) were grafted onto the surface of $\mathrm{TiO}_{2}$ nanoparticles for the first time. 


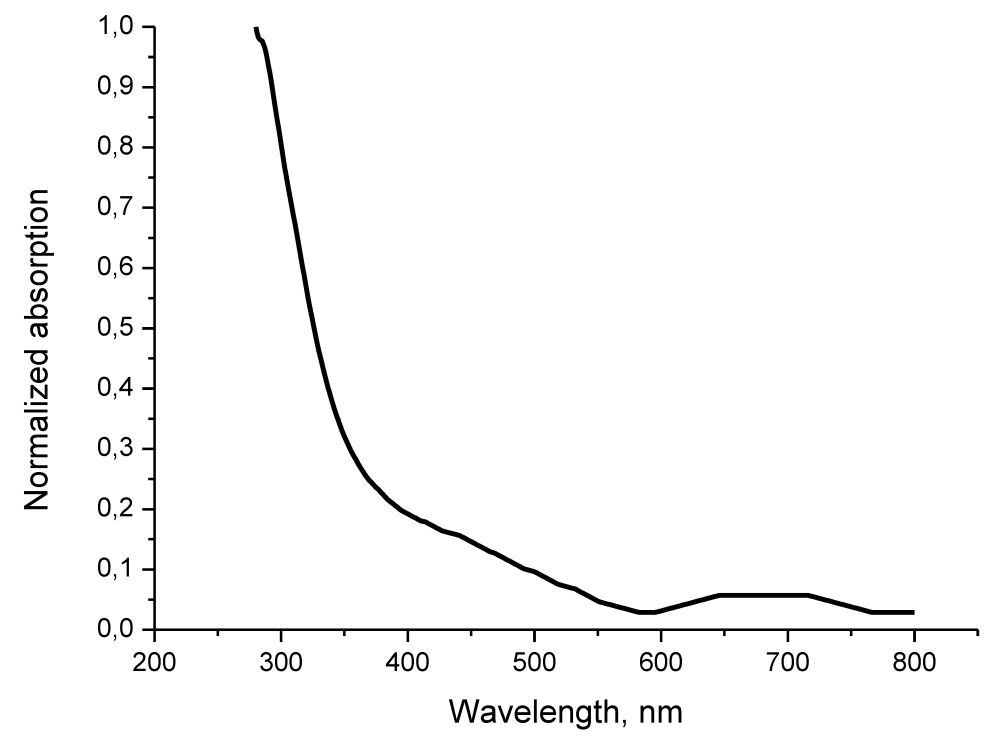

FIG. 7. UV spectrum of $\mathrm{TiO}_{2}$-APTES-BiB-PMAA nanoparticles in water

\section{Acknowledgements}

The work is supported by the Russian Science Foundation (Project No. 19-13-00442).

\section{References}

[1] Byrne C., Subramanian G., Pillai S.C. Recent advances in photocatalysis for environmental applications. Journal of Environmental Chemical Engineering, 2018, 6, P. 3531-3555.

[2] Colmenares J.C., Varma R.S., Lisowski P. Sustainable hybrid photocatalysts: titania immobilized on carbon materials derived from renewable and biodegradable resources. Green Chemistry, 2016, 18, P. 5736-5750.

[3] Krasilin A.A., Bodalyov I.S., et al. On an adsorption/photocatalytic performance of nanotubular $\mathrm{Mg}_{3} \mathrm{Si}_{2} \mathrm{O}_{5}(\mathrm{OH})_{4} / \mathrm{TiO}_{2}$ composite. Nanosystems: Physics, Chemistry, Mathematics, 2018, 9, P. 410-416.

[4] Kolesnik I.V., Lebedev V.A., Garshev A.V. Optical properties and photocatalytic activity of nanocrystalline $\mathrm{TiO}_{2}$ doped by $3 \mathrm{~d}-\mathrm{metal}_{\text {ions. }}$ Nanosystems: Physics, Chemistry, Mathematics, 2018, 9, P. 401-409.

[5] Kozlov D.A., Lebedev V.A., et al The microstructure effect on the $\mathrm{Au} / \mathrm{TiO}_{2}$ and $\mathrm{Ag} / \mathrm{TiO}_{2}$ nanocomposites photocatalytic activity. Nanosystems: Physics, Chemistry, Mathematics, 2018, 9, P. 266-278.

[6] Szanyi J., Kwak J.H., Photo-catalytic oxidation of acetone on a $\mathrm{TiO}_{2}$ powder: An in situ FTIR investigation. Journal of Molecular Catalysis A: Chemistry, 2015, 406, P. 213-223.

[7] Ulyanova E.S., Zamyatin D.A., Kolosov V.Yu., Shalaeva E.V. Visible light photoluminescence in $\mathrm{TiO}_{2} / \mathrm{CdS}$ nanopowders synthesized by sol-gel route: effect of gel aging time. Nanosystems: Physics, Chemistry, Mathematics, 2020, 11, P. 480-487.

[8] Zavialova A.Yu., Bugrov A.N., et al Structure and photoluminescent properties of $\mathrm{TiO}_{2}:$ Eu $^{3+}$ nanoparticles synthesized under hydro and solvothermal conditions from different precursors. Nanosystems: Physics, Chemistry, Mathematics, 2019, 10, P. $361-373$.

[9] Wang Y., Sun C.,et al. The Application of Nano- $\mathrm{TiO}_{2}$ Photo Semiconductors in Agriculture. Nanoscale Research Letters, 2016, 11, 529.

[10] Morozova P.A., Petukhov D.I. Preparation of $\mathrm{Au} / \mathrm{TiO}_{2} /$ Ti memristive elements via anodic oxidation. Nanosystems: Physics, Chemistry, Mathematics, 2017, 8, P. 823-829.

[11] Ganeshraja A.S., Anbalagan K. Participation of nanocrystalline $\mathrm{TiO}_{2}$ Surface in the electron transfer between semiconductor solid and adsorbed cobalt(III)-RPY complex. Nanosystems: Physics, Chemistry, Mathematics, 2013, 4, P. $276-287$.

[12] Gazquez M.J., Bolivar J P., Garcia-Tenorio R., Vaca F. A review of the production cycle of titanium dioxide pigment. Materials Sciences and Applications, 2014, 5, P. 441-458.

[13] Dimkpa C.O. Can nanotechnology deliver the promised benefits without negatively impacting soil microbial life. Journal of Basic Microbiology, 2014, 54, P. 889-904.

[14] Peller J., Wies O., Kamat P.V. Hydroxyl Radical's Role in the Remediation of a Common Herbicide, 2,4-Dichlorophenoxyacetic Acid (2,4-D). Journal of Physical Chemistry A, 2004, 108, P. 10925-10933.

[15] Hou J., Wang X., et al. Toxicity and mechanisms of action of titanium dioxide nanoparticles in living organisms. Journal of environmental sciences (China), 2019, P. 7540-7553.

[16] Guan H.N., Chi D.F., Yu J., Li X.C. A novel photodegradable insecticide: preparation, characterization and properties evaluation of nanoImidacloprid. Pesticide Biochemistry and Physiology, 2008, 92, P. 83-91.

[17] Ahmed S., Rasul M.G., Brown R., Hashib M.A. Influence of parameters on the heterogeneous photocatalytic degradation of pesticides and phenolic contaminants in wastewater. J. Environ. Manage, 2011, 92, P. 311-330.

[18] Parida K.M., Sahu N., et al. Preparation, characterization, and photo-catalytic activity of sulfate-modified titania for degradation of methyl orange under visible light. J Colloid Interface Sci., 2008, 318, P. 231-237. 
[19] Aragay G., Pino F., Merkoç I.A. Nanomaterials for sensing and destroying pesticides. Chemical Reviews, 2012, 112, P. 5317-5338.

[20] Lee K., Ku H., Pak D. OH radical generation in a photocatalytic reactor using $\mathrm{TiO}_{2}$ nanotube plates. Chemosphere, 2016, 149, P. 114-120.

[21] Devipriya S., Yesodharan S. Photocatalytic degradation of pesticide contaminants in water. Solar Energy Materials \& Solar Cells, 2005, 86, P. 309-348.

[22] Rabindranathan S., Devipriya S., Yesodharan S. Photocatalytic degradation of phosphamidon on semiconductor oxides. Journal of Hazardous Materials, 2003, 102, P. 217-229.

[23] Lhomme L., Brosillon S., Wolbert D. Photocatalytic degradation of pesticides in pure water and a commercial agricultural solution on TiO 2 coated media. Chemosphere, 2008, 70, P. 381-386.

[24] Marien C.B.D., Cottineau T., Robert D., Drogui P. $\mathrm{TiO}_{2}$ nanotube arrays: influence of tube length on the photocatalyticdegradation of Paraquat. Applied Catalysis B: Environmental, 2016, 194, P. 1-6.

[25] Bzdon S., Goralski J., et al. Radiation-induced synthesis of Fe-doped $\mathrm{TiO}_{2}$ : characterization and catalytic properties. Radiation Physics and Chemistry, 2012, 81, P. 59-63.

[26] Attarchi N., Montazer M., Toliyat T. Ag/TiO $2 / \beta-C D$ nano composite: preparation and photo catalytic properties for methylene blue degradation. Applied Catalysis A: General, 2013, 467, P. 107-116.

[27] Zhang X., Wu F., et al. Photocatalytic degradation of 4,4'-biphenol in $\mathrm{TiO}_{2}$ suspension in the presence of cyclodextrins: a trinity integrated mechanism. Journal of Molecular Catalysis A: Chemistry, 2009, 301, P. 134-139.

[28] Ramos-Delgado N.A., Gracia-Pinilla M.A., et al. Solar photocatalytic activity of $\mathrm{TiO}_{2}$ modified with WO3 on the degradation of an organophosphorus pesticide. Journal of Hazardous Mater, 2013, 263, P. 36-44.

[29] Vamathevan V., Amal R., et al. Silver metallization of titania particles: effects on photoactivity for the oxidation of organics. Journal of Gastrointestinal Surgery, 2015, 19, P. 1-6.

[30] Behnajady M.A., Modirshahla N., Hamzavi R. Kinetic study on photocatalytic degradation of C.I. acid yellow 23 by ZnO photocatalyst. Journal of Hazardous Materials, 2006, 133, P. 226-232.

[31] Leghari S.A.K., Sajjad S., Chen F., Zhang J. WO3/TiO 2 composite with morphology change via hydrothermal template-free route as an efficient visible light photocatalyst. Chemical Engineering Journal, 2011, 166, P. 906-915.

[32] Yao K.S., Wang D.Y., et al. Photocatalytic bactericidal effect of $\mathrm{TiO}_{2}$ thin film on plant pathogens. Surface \& Coatings Technology, 2007, 201, P. 6886-6888.

[33] Yao K.S., Wang D.Y., et al. Photocatalytic disinfection of phytopathogenic bacteria by dye-sensitized $\mathrm{TiO}_{2}$ thin film activated by visible light. Surface \& Coatings Technology, 2007, 202, P. 1329-1332.

[34] Cui H.X., Yang G.C., et al. Biological effects of PAS $\mathrm{TiO}_{2}$ sol on disease control and photosynthesis in cucumber (Cucumis sativus L). Australian Journal of Crop Science, 2013, 7, P. 99-103.

[35] Shilova O.A., Khamova T.V., et al. Synthesis and Research of Functional Layers Based on Titanium Dioxide Nanoparticles and Silica Sols Formed on the Surface of Seeds of Chinese Cabbage. Russian Journal of Applied Chemistry, 2020, 93 (1), P. $25-34$.

[36] Khot L.R., Ehsani R., et al. Applications of nanomaterials in agricultural production and crop protection. A review. Crop Protection, 2012, 35, P. 64-70.

[37] Zheng L., Hong F., Lu S., Liu C. Effect of nano- $\mathrm{TiO}_{2}$ on strength of naturally aged seeds and growth of spinach. Biological Trace Element Research, 2005, 104, P. 83-91.

[38] Song G., Gao Y., et al. Physiological effect of anatase $\mathrm{TiO}_{2}$ nanoparticles on Lemna minor. Environmental Toxicology and Chemistry, 2012, 31, P. 2147-2152.

[39] Yang F., Liu C., et al. The improvement of spinach growth by nano-anatase $\mathrm{TiO}_{2}$ treatment is related to nitrogen photoreduction. Biological Trace Element Research, 2007, 119, P. 77-88.

[40] Raliya R., Biswas P., Tarafdar J.C., $\mathrm{TiO}_{2}$ nanoparticle biosynthesis and its physiological effect on mung bean (Vigna radiata L). Biotechnology Reports, 2015, 5, P. 22-26.

[41] Palmqvist N.G.M., Bejai S., et al. Nano titania aided clustering and adhesion of beneficial bacteria to plant roots to enhance crop growth and stress management. Scientific Reports, 2015, 5, 10146.

[42] Wang Y., Liu L., et al. Synthesis of Modified $\mathrm{TiO}_{2}$ Nanoparticles with Polyacrylonitrile and Poly(hydroxyethyl acrylate) via ATRP. Chemistry Select, 2020, 5, P. 4695-4700.

[43] Kopec M., Spanjers J., et al. Surface-initiated ATRP from polydopamine-modified $\mathrm{TiO}_{2}$ nanoparticles. European Polymer Journal, 2018, 106, P. 291-296.

[44] Ensafi A.A., Khoddami E., Nabiyan A., Rezaei B. Study the role of poly(diethyl aminoethyl methacrylate) as a modified and grafted shell for $\mathrm{TiO}_{2}$ and $\mathrm{ZnO}$ nanoparticles, application in flutamide delivery. Reactive \& Functional Polymers, 2017, 116, P. 1-8.

[45] Park J.T., Lee C.S., Park C.H., Kim J.H. Preparation of $\mathrm{TiO}_{2} / \mathrm{Ag}$ binary nanocomposite as high-activity visible-light-driven photocatalyst via graft polymerization. Chemical Physics Letters, 2017, 685, P. 119-126.

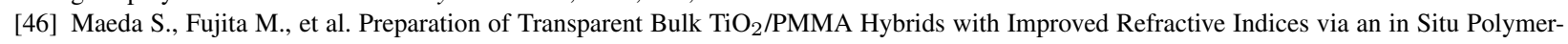
ization Process Using $\mathrm{TiO}_{2}$ Nanoparticles Bearing PMMA Chains Grown by Surface-Initiated Atom Transfer Radical Polymerization. ACS Applied Materials \& Interfaces, 2016, 8, P. 34762-34769.

[47] Mai T.B., Tran T.N., et al. Synthesis and characterization of poly(oligoethyleneglycol methacrylate)-g-TiO 2 nanocomposites via surfaceinitiated ARGET ATRP. Molecular Crystals and Liquid Crystals, 2014, 602, P. 118-125.

[48] Liu L., Chen H., Yang F. Enhancing membrane performance by blending ATRP grafted PMMA-TiO 2 or PMMA-PSBMA-TiO $_{2}$ in PVDF. Separation and Purification Technology, 2014, 133, P. 22-31.

[49] Zhang G., Lu S., et al. Novel polysulfone hybrid ultrafiltration membrane prepared with $\mathrm{TiO}_{2}$-g-HEMA and its antifouling characteristics. Journal of Membrane Science, 2013, 436, P. 163-173.

[50] Cui W.-W., Tang D.-Y., Gong Z.-L. Electrospun poly(vinylidene fluoride)/poly(methyl methacrylate) grafted TiO 2 composite nanofibrous membrane as polymer electrolyte for lithium-ion batteries. Journal of Power Sources, 2013, 223, P. $206-213$.

[51] Gong Z.-L., Tang D.-Y., Guo Y.-D. The fabrication and self-flocculation effect of hybrid $\mathrm{TiO}_{2}$ nanoparticles grafted with poly(Nisopropylacrylamide) at ambient temperature via surface-initiated atom transfer radical polymerization. Journal of Materials Chemistry, 2012, 22, P. 16872-16879. 
[52] Chen H., Pan S., et al. Preparation of thermo-responsive superhydrophobic $\mathrm{TiO}_{2} /$ poly(N-isopropylacrylamide) microspheres. Applied Surface Science, 2012, 258, P. 9505-9509.

[53] Xiong L., Liang H., Wang R., Chen L. A novel route for the synthesis of poly(2-hydroxyethyl methacrylate-co-methyl methacrylate) grafted titania nanoparticles via ATRP. Journal of Polymer Research, 2011, 18, P. 1017-1021.

[54] Park J.T., Koh J.H., et al. Proton-conducting nanocomposite membranes based on P(VDF-co-CTFE)-g-PSSA graft copolymer and TiO 2 -PSSA nanoparticles. International Journal of Hydrogen Energy, 2011, 36, P. 1820-1827.

[55] Akpolat L.B., Cakir B.A., Topel O., Hoda N. Synthesis of $\mathrm{TiO}_{2}$ nanoparticles by self-assembling reverse micelle cores of PS-b-PAA for functional textile applications. Materials Research Bulletin, 2015, 64, P. 117-122.

[56] Shilova O.A., Panova G.G., et al. Properties, and Phytoprotective Functions of Titanium Dioxide Nanopowders and Their Aqueous Suspensions. Russian Journal of Inorganic Chemistry, 2021, 66, P. 765-772.

[57] Mueller R., Kammler H.K., Wegner K., Pratsinis S.E. OH Surface Density of $\mathrm{SiO}_{2}$ and $\mathrm{TiO}_{2}$ by Thermogravimetric Analysis. Langmuir, 2003, 19, P. 160-165.

[58] Ou B., Li D., et al. Functionalized $\mathrm{TiO}_{2}$ nanoparticle containing isocyanate groups. Material Chemistry and Physics, 2012 , 135, P. $1104-1107$.

[59] Zhao J., Milanova M., Warmoeskerken M.M.C.G., Dutschk V. Surface modification of $\mathrm{TiO}_{2}$ nanoparticles with silane coupling agents. Colloids and Surfaces A: Physicochemical and Engineering Aspects, 2012, 413, P. 273- 279.

[60] Yakimansky A.V., Meleshko T.K., et al. Novel Regular Polyimide-graft-Poly(methacrylic acid) Brushes: Synthesis and Possible Applications as Nanocontainers of Cyanoporphyrazine Agents for Photodynamic Therapy. Journal of Polymer Science, Part A: Polymer Chemistry, 2013, 51, P. 4267-4281.

[61] Kashina A.V., Meleshko T.K., et al. Synthesis of Pentablock Copolymers of the Mixed Linear-Brush Topology by Controlled Radical Polymerization and Ring-Opening Polymerization Reactions. Polymer Science, Series C, 2019, 61, P. 174-185.

[62] Pugachevskii M.A. Ultraviolet absorption spectrum of laser-ablated titanium dioxide nanoparticles. Technical Physics Letters, 2013, 39, P. 3638.

[63] Raghuraman G.K., Rühe J., Dhamodharan R. Grafting of PMMA brushes on titania nanoparticulate surface via surface-initiated conventional radical and "controlled" radical polymerization (ATRP). Journal of Nanoparticle Research, 2008, 10, P. $415-427$. 